\title{
O financiamento dos programas Federais de esporte e lazer no Brasil (2004 a 2008)
}

\author{
Bárbara Schausteck de Almeida * \\ Wanderley Marchi Júnior **
}

\begin{abstract}
RESUMO: Propomos nessa pesquisa responder as seguintes questões: quanto, em recursos financeiros, os programas de esporte e lazer receberam sob a forma de gastos diretos do governo federal e através de repasses aos estados e municípios entre 2004 e 2008? Que fatores podem justificar os investimentos prioritários do governo federal nesse período? Através da coleta dos dados da Controladoria-Geral da União, mostramos que o somatório investido pelo governo federal priorizou o esporte de alto rendimento. Com pressupostos da Sociologia reflexiva de Pierre Bourdieu, esboçamos algumas justificativas para entender essa prioridade no período abordado envolvendo a compreensão das lógicas do campo político.

Palavras-chave: Política. Esportes. Financiamento Governamental. Brasil.
\end{abstract}

\section{INTRODUÇÃO}

A preocupação política com o esporte foi institucionalizada na legislação brasileira pela primeira vez no governo Vargas, através do Decreto-lei 3.199 de 1941 e atualmente está presente no Artigo 217 da Constituição Federal de 1988. Nesse interstício temporal, a administração do esporte passou da subordinação governamental

*Bacharel e mestre em Educação Física. Membro da Asociación Latinoamericana de Estudios Socioculturales del Deporte (ALESDE), da North American Society for the Sociology of Sport (NASSS) e International Sport Sociology Association (ISSA). Curitiba, PR, Brasil. E-mail: barbara.edf@ufpr.br

**Graduado em Educação Física e Técnico Desportivo. Mestre e Doutor em Educação Física. Professor efetivo nos programas de pós-graduação nível de mestrado e doutorado nos departamentos de Educação Física e de Ciências Sociais da Universidade Federal do Paraná. Coordena o grupo de pesquisa do CNPq Centro de Pesquisas em Esporte, Lazer e Sociedade (CEPELS) e do GT Sociologia del Deporte y Esparciamento da Associação Latinoamericana de Sociologia. Vice presidente da Asociación Latinoamericana de Estudios Socioculturales del Deporte (ALESDE). Curitiba, PR, Brasil. E-mail: marchijr@ufpr.br 


\section{Artigos Originais Bárbara de Almeida e Wanderley M. Júnior}

para a atual autonomia das entidades gestoras, priorizada no primeiro inciso do referido Artigo 217.

Porém essa autonomia na administração não significou necessariamente a autonomia financeira com relação ao Estado. No caso brasileiro, a dependência financeira estatal se manifesta, de alguma forma, em todas as confederações de modalidades olímpicas (ALMEIDA, 2010), apesar da existência de um potencial financiamento de suas atividades através de patrocínios privados, como se observa em outros países.

Entretanto, ainda que o governo federal subsidie de inúmeras formas o esporte de alto rendimento, a destinação de recursos públicos para essa manifestação deve ser somente "em casos específicos" conforme a Constituição Federal de 1988 prescreve. No artigo citado, no segundo inciso, consta que no fomento de práticas esportivas formais e não formais pelo Estado deve ser observada "[...] a destinação de recursos públicos para a promoção prioritária do desporto educacional e, em casos específicos, para a do desporto de alto rendimento" (BRASIL, 1988).

Ao questionar se os investimentos diretos do governo federal, ou seja, através do Ministério do Esporte (ME) e de outros ministérios que também investem em ações de esporte e lazer, são prioritários ao esporte educacional, chegamos às perguntas norteadoras dessa pesquisa: quanto, em recursos financeiros, os programas de esporte e lazer receberam sob a forma de gastos diretos do governo federal e através dos repasses aos estados e municípios entre 2004 e 2008 ? Que fatores podem justificar os investimentos prioritários do governo federal nesse período?

Assim, estabelecemos como objetivo principal dessa pesquisa demonstrar os valores e possíveis razões dos investimentos do governo federal, sob a forma de gastos diretos e repasses aos estados e municípios, em ações de esporte e lazer no período de 2004 a 2008. Com relação aos objetivos específicos, pretendemos: (1) recuperar algumas contribuições teóricas de Pierre Bourdieu sobre o campo político e que auxiliam na compreensão do quadro a ser abordado; (2) demonstrar os

Movimento, Porto Alegre, v. 16, n. 04, p. 73-92, outubro/dezembro de 2010. 
valores financeiros investidos nos programas de esporte e lazer no período já citado; e (3) discutir, com o suporte da perspectiva teórica escolhida, fatores que justificam a opção prioritária do governo federal em determinadas manifestações esportivas.

A disponibilidade dos dados na fonte de coleta eleita limitou o recorte temporal. As informações estavam disponíveis a partir de 2004 e, no momento de realização desta pesquisa, os dados de 2009 ainda estavam incompletos.

\section{Procedimentos Metodológicos}

Essa pesquisa se caracteriza como um estudo: (1) documental quanto ao procedimento técnico; (2) quantitativo e qualitativo quanto à abordagem do problema; (3) exploratório quanto ao seu objetivo; e (4) de cunho sociológico quanto às análises dos dados (SILVA; MENEZES, 2001).

A coleta de dados ocorreu a partir do endereço eletrônico na internet <www.transparencia.gov.br>, no qual são publicados todos os gastos públicos federais. Idealizado pela Controladoria-Geral da União (CGU), objetiva o livre acesso e controle dos cidadãos sobre os investimentos federais mensais de cada órgão superior (CONTROLADORIA-GERAL DA UNIÃO, 2010).

$\mathrm{Na}$ organização dos dados, não existe nenhum tratamento analítico das informações. Por isso, caracterizamos essa pesquisa como documental.

A abordagem quantitativa está presente no levantamento, tratamento e interpretação dos valores investidos em ações de esporte e lazer pelos órgãos superiores e pelos repasses aos estados e municípios.

Nesse endereço eletrônico, após a opção de seleção dos dados de gastos diretos do governo e da transferência de recursos por ação governamental, nos anos de 2004 a 2008, realizamos o download do banco de dados no formato "xls" (do software Microsoft Office

Movimento, Porto Alegre, v. 16, n. 04, p. 73-92, outubro/dezembro de 2010. 


\section{Artigos Originais Bárbara de Almeida e Wanderley M. Júnior}

Excel) e filtramos as informações selecionando as ações que tinham como nome da função "Desporto e lazer" (código 27).

Após essa etapa, utilizamos recursos estatísticos básicos do mesmo software, onde somamos o valor investido em cada um dos programas federais da área, organizamos em tabelas e realizamos o cálculo percentual para a construção dos gráficos.

Já a abordagem qualitativa está presente na interpretação e contextualização das informações coletadas, seus significados e interrelações com o mundo social. Pela mesma razão se dá a característica exploratória da pesquisa, já que essa investigação preliminar visa traçar alguns indícios da abordagem dada ao esporte pelo financiamento governamental.

Ao utilizarmos o referencial teórico do autor francês Pierre Bourdieu, caracterizamos esta pesquisa como de cunho sociológico. Explicitaremos parte de seu arcabouço teórico para compreensão de algumas lógicas do campo político e alguns usos potenciais do esporte nesse contexto.

Assim, esse artigo estará dividido em duas grandes seções: os resultados e a discussão. A primeira parte dos resultados (Campo político e esporte) traz algumas colaborações para compreensão da lógica do campo político e as possíveis aproximações com o esporte, de acordo com Bourdieu. A segunda parte dos resultados (Os investimentos dos órgãos superiores e repasses aos estados e municípios para programas de esporte e lazer no Brasil) aborda o financiamento das ações federais para o esporte e lazer, considerando essas duas possibilidades de investimentos. E a discussão finaliza o texto com a abordagem da situação apresentada baseada no referencial teórico.

\section{Resultados}

\subsection{Campo político e ESPORTE}

Através da teoria dos campos, idealizada por Pierre Bourdieu, a gênese de um campo político ou burocrático teria ocorrido na transição do Estado dinástico para o Estado burocrático.

Movimento, Porto Alegre, v. 16, n. 04, p. 73-92, outubro/dezembro de 2010. 
No Estado dinástico, há uma grande concentração de capital simbólico na "casa do rei", que, progressivamente, teve seu poder descentralizado até tornar-se uma "oligarquia dinástica". Nesse processo de longa duração, houve um aumento no número de agentes (pessoas e instituições), forças e disputas que ocorrem para o monopólio de decisões ou "para o monopólio de manipulação legítima dos bens públicos", compondo um crescimento na cadeia de interdependências entre autoridades e responsabilidades que formam o Estado burocrático (BOURDIEU, 2005, p. 41).

O Estado burocrático se constitui como uma instância superior a todas as outras, por concentrar diferentes espécies de capital (econômico, militar, cultural, jurídico e simbólico), que podem ser entendidos como qualidades ou potencialidades que manifestam o poder. Para essa característica diferencial, Bourdieu considera a existência de um capital propriamente estatal denominado metacapital, que permite ao Estado um grande poder de intervenção e influência sobre os outros campos (BOURDIEU; WACQUANT, 2005). Assim, há a possibilidade de pensar o Estado como um metacampo, que determina as regras para os outros campos, sendo também um lócus de disputas entre os dominantes desses outros campos (BOURDIEU, 2005).

Por isso, o Estado será compreendido como um conjunto de campos administrativos ou burocráticos no qual ocorrem lutas entre os agentes que irão legislar e regulamentar práticas diversas por meio de normas e políticas (BOURDIEU; WACQUANT, 2005, p. 169).

Outra característica relevante colocada por Bourdieu quando trata do campo político é a existência da mão esquerda e mão direita do Estado. Esses termos seriam representativos de dois conjuntos distintos: a mão esquerda, representada pelos agentes dos ministérios relacionados às políticas sociais; e a mão direita, representada pelos ministérios relacionados à economia, como os bancos e agentes dos gabinetes ministeriais, entre outros burocratas (BOURDIEU, 1998).

Movimento, Porto Alegre, v. 16, n. 04, p. 73-92, outubro/dezembro de 2010. 


\section{Artigos Originais Bárbara de Almeida e Wanderley M. Júnior}

Esses agentes caracterizam as principais lutas dentro do campo político, no qual, sob a análise do capital econômico, a mão direita é dominante e a mão esquerda dominada, constantemente lutando entre si pela dominância sob análise do capital simbólico. Sobre essas terminologias é interessante realizar uma abstração para localizar o esporte dentro desse universo.

Se pensarmos no campo político, o esporte é um subcampo componente da mão esquerda do Estado, tido muitas vezes como meio de "resolver as mazelas sociais" ao impedir a entrada ou retirar os jovens da dependência química ou da violência.

É comum vermos políticas de governo que utilizam deste discurso para implantar programas sociais esportivos cujos profissionais devem "exercer as funções ditas "sociais" - isto é, compensar, sem dispor de todos os meios necessários, os efeitos e carências mais intoleráveis da lógica do mercado", da mesma forma que outros agentes da mão esquerda, como policiais, assistentes sociais e educadores (BOURDIEU, 2003, p. 218).

Mesmo o esporte de alto rendimento pode ser observado como estando na mão esquerda do Estado quando, mesmo "sem dispor de todos os meios necessários", as suas conquistas em grandes eventos internacionais são acompanhadas de discursos que enaltecem o esforço de cidadãos de uma nação, numa tentativa de resgatar o descrédito e a descrença de uma população com dificuldades múltiplas.

Porém, se pensarmos especificamente no subcampo político brasileiro para o esporte, o esporte de rendimento estaria na mão direita enquanto as manifestações do esporte escolar e como prática de lazer estão na mão esquerda, sob o viés do capital econômico.

De forma preliminar, vê-se que o campo do esporte está numa posição dominada perante outros campos dentro do Estado. Porém, os dominantes no campo esportivo buscam uma posição de dominância também neste metacampo. Esse subsídio teórico fornecido por Bourdieu nos auxilia na percepção das posições e disposições dos agentes envolvidos no campo esportivo.

Movimento, Porto Alegre, v. 16, n. 04, p. 73-92, outubro/dezembro de 2010. 
Ainda como apresentação dos resultados, discorremos sobre alguns dos aspectos organizacionais do Ministério do Esporte (ME) e o financiamento das ações relacionadas ao esporte e lazer no contexto federal.

3.2 Os IVESTIMENTOS DE ÓRGÃOS SUPERIORES E REPASSES AOS ESTADOS E MUNICÍPIOS PARA PROGRAMAS DE ESPORTE E LAZER NO BRASIL

O ME é atualmente o órgão público federativo máximo do esporte no Brasil. Através da compreensão de sua estrutura e principais ações, buscaremos aqui mapear o panorama político do esporte no país com um entendimento das inter-relações que esses campos possuem.

O esporte esteve sob a responsabilidade de diferentes órgãos públicos federais na história política brasileira. Iniciou-se como objeto da Divisão de Educação Física do Ministério da Educação e Cultura (1937), tornou-se Departamento de 1970 até 1978, quando se transformou em Secretaria de Educação Física e Desporto. A vinculação ao Ministério da Educação permaneceu até 1989, quando houve a desvinculação para criação da Secretaria de Desportos da Presidência da República, cuja designação persistiu até 1995. Neste ano, essa secretaria tornou-se o Instituto Nacional de Desenvolvimento do Esporte (INDESP), subordinado ao Ministério Extraordinário do Esporte. De 1998 a 2000, o INDESP esteve vinculado ao Ministério do Esporte e Turismo, sendo substituído pela Secretaria Nacional de Esporte (BRASIL, 2009).

Somente em janeiro de 2003 o esporte tornou-se objeto único de um ministério. Como ME, foi dirigido por dois ministros: Agnelo Queiroz, de 2003 a 2006, e Orlando Silva Junior, desde 2006. Ambos fazem parte do Partido Comunista do Brasil (PC do B), partido de esquerda aliado do governo federal do período e que tem no esporte sua única representatividade ministerial.

Movimento, Porto Alegre, v. 16, n. 04, p. 73-92, outubro/dezembro de 2010. 
A atuação do ME no esporte se dá a partir de três manifestações, conforme a Constituição Federal de 1988: educação, participação e rendimento.

Quanto aos recursos financeiros, o montante efetivamente investido pelo governo federal de 2004 a 2008 com programas de esporte e lazer foi de R \$732,86 milhões. Desse total, R \$ 661,71 milhões (ou 90\%) foram investidos pelo ME e R \$ 71,14 milhões (ou $10 \%$ ) por outros órgãos superiores (CONTROLADORIA-GERAL DA UNIÃO, 2004a; 2005a; 2006a; 2007a; 2008a). O investimento de cada órgão pode ser visto na tabela a seguir.

Tabela 1: valores investidos em ações de esporte e lazer por Órgão Superior Federal - 2004-2008

\begin{tabular}{lr}
\hline Órgão superi or & Em R\$ \\
1- Agricultura, pecuária e abastecimento & $40.154,88$ \\
\hline 2- Ciência e tecnologia & $11.084 .806,81$ \\
\hline 3- Defesa & $22.487 .042,12$ \\
\hline 4- Educação & $29.173 .479,66$ \\
\hline 5- Esporte & $661.716 .980,47$ \\
\hline 6- Fazenda & $279.693,91$ \\
\hline 7- Planejamento, orçamento e gestão & $1.105 .807,06$ \\
\hline 8- Presidência da República & $6.115 .245,33$ \\
\hline 9- Saúde & $437.567,33$ \\
\hline 10- Turismo & $419.553,71$ \\
\hline
\end{tabular}

Fonte: A autora (2010) com base nos dados de Controladoria-Geral da União (2004a; 2005a; 2006a; 2007a; 2008a).

Em 2004, somente cinco ministérios investiram verbas no esporte. Já em 2007, ano de realização dos Jogos Pan-Americanos do Rio de Janeiro (Rio 2007), houve o investimento por parte de nove ministérios, o que ratifica a mobilização pública para sediar esse evento.

Dentre as verbas investidas por outros ministérios, notamos que, nos programas relacionados ao esporte participação e ao esporte educacional, a maior parte dos investimentos é proveniente de outros órgãos superiores e não do próprio ME.

Movimento, Porto Alegre, v. 16, n. 04, p. 73-92, outubro/dezembro de 2010. 
Tabela 2: Valores investidos por Órgão Superior Federal e total em cada programa de esporte e lazer - 2004-2008

\begin{tabular}{|c|c|c|c|}
\hline Programa & $\begin{array}{r}\text { Ministério do } \\
\text { Esporte }\end{array}$ & Outros órgãos & Total \\
\hline Apoio Administrativo & $82.155 .067,15$ & $283.456,20$ & $82.438 .523,35$ \\
\hline $\begin{array}{l}\text { Brasil no Esporte de Alto } \\
\text { Rendimento }\end{array}$ & $63.653 .171,80$ & $6.510 .906,28$ & $70.164 .078,08$ \\
\hline Esporte e Lazer na Cidade & $2.250 .689,02$ & $8.620 .387,49$ & $10.871 .076,51$ \\
\hline Esporte Solidário & 0,00 & $142.882,02$ & $142.882,02$ \\
\hline $\begin{array}{l}\text { Gestão das Políticas de } \\
\text { Esporte e de Lazer }\end{array}$ & $19.750 .170,25$ & $2.272 .302,26$ & $22.022 .472,51$ \\
\hline Inclusão Social Pelo Esporte & $1.548 .299,28$ & 0,00 & $1.548 .299,28$ \\
\hline Rumo ao Pan 2007 & $481.748 .277,77$ & $38.579 .419,80$ & $520.327 .697,57$ \\
\hline $\begin{array}{l}\text { Vivência e Iniciação } \\
\text { Esportiva Educacional - } \\
\text { Segundo Tempo }\end{array}$ & $10.297 .066,71$ & $15.035 .743,28$ & 25.332.809,99 \\
\hline
\end{tabular}

Fonte: A autora (2010) com base nos dados de Controladoria-Geral da União (2004a; 2005a; 2006a; 2007a; 2008a).

Citamos o programa "Esporte e Lazer na Cidade", no qual outros órgãos superiores investiram $\mathrm{R} \$ 8,62$ milhões, valor quase quatro vezes maior que a quantia investida pelo ME. No programa "Vivência e Iniciação Esportiva Educacional - Segundo Tempo", outros órgãos investiram $\mathrm{R} \$ 15$ milhões enquanto o $\mathrm{ME}$ investiu $\mathrm{R} \$ 10$ milhões. Porém, o maior alvo de investimentos dos outros ministérios também foi o Rio 2007, com R \$38,58 milhões.

Por essa lista de ações de esporte e lazer do governo federal é possível identificar que o maior percentual investido (80\%) foi em esporte de alto rendimento no período observado, nas ações "Brasil no Esporte de Alto Rendimento - Brasil Campeão" e "Rumo ao Pan 2007". Se considerarmos que $11 \%$ é gasto com a administração dos programas, nas chamadas despesas de investimentos ${ }^{1}$, vemos que resta menos de $9 \%$ dos recursos para as ações de esporte escolar e participação.

\footnotetext{
${ }^{1}$ As categorias econômicas das despesas públicas são classificadas como despesas correntes e despesas de capital. Uma das despesas correntes são as despesas de custeio, para manutenção dos serviços nas quais se incluem as ações de esporte e lazer abordadas. Já nas despesas de capital estão as despesas de investimento, necessárias para o planejamento e execução de obras, aquisição de bens, instalações, equipamentos, etc. (CARVALHO, 2007).
}

Movimento, Porto Alegre, v. 16, n. 04, p. 73-92, outubro/dezembro de 2010. 


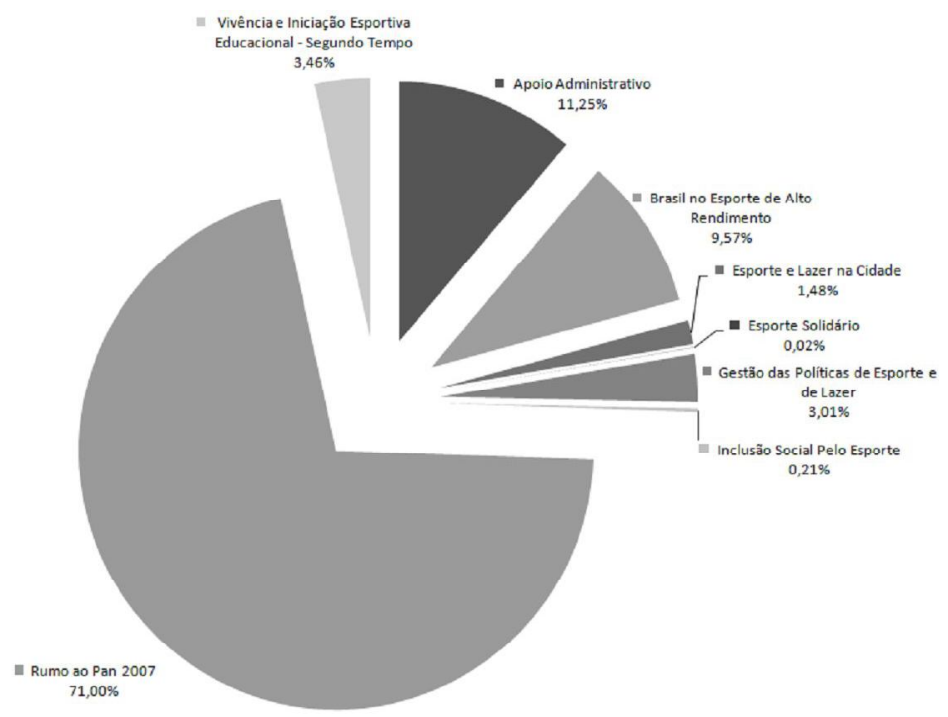

Figura 1. Gráfico Percentual de Investimentos do Governo Federal em suas Ações de Governo em Esporte e Lazer - 2004-2008

Fonte: A autora (2010) com base nos dados de Controladoria-Geral da União (2004a; 2005a; 2006a; 2007a; 2008a).

Os recursos investidos por outros ministérios aumentaram de forma relevante o direcionamento do governo federal para os programas educacionais e de participação, porém não o suficiente para atingir os gastos com esporte de rendimento, sendo esta a destinação de recursos prioritária dos órgãos superiores que investiram em esporte e lazer no período de 2004 a 2008.

É importante salientar que esses valores são referentes ao gasto direto dos órgãos federais com as ações de esporte e lazer. No Brasil, além dos gastos diretos, existe a possibilidade de investimentos federais via transferência de recursos aos estados e municípios. Dessa forma, os recursos são solicitados pelos deputados federais (individualmente, pelos seus partidos ou pelas regiões que atendem) via emendas parlamentares. Se as solicitações forem aceitas, as

Movimento, Porto Alegre, v. 16, n. 04, p. 73-92, outubro/dezembro de 2010. 
verbas são repassadas. Algumas possibilidades de interpretação sobre aspectos positivos e negativos dessa forma de investimento serão discutidos a seguir.

O investimento em esporte e lazer, no período de 2004 a 2008, por esses repasses, foi de R $\$ 1,88$ bilhão (CONTROLADORIAGERAL DA UNIÃO, 2004b; 2005b; 2006b; 2007b; 2008b). Desse valor, divergindo ao caso dos órgãos superiores, houve um repasse percentualmente maior para ações de esporte participativo e educacional através dos programas "Esporte e Lazer na Cidade" e "Vivência e Iniciação Esportiva Educacional - Segundo Tempo", conforme pode ser observado no gráfico abaixo.

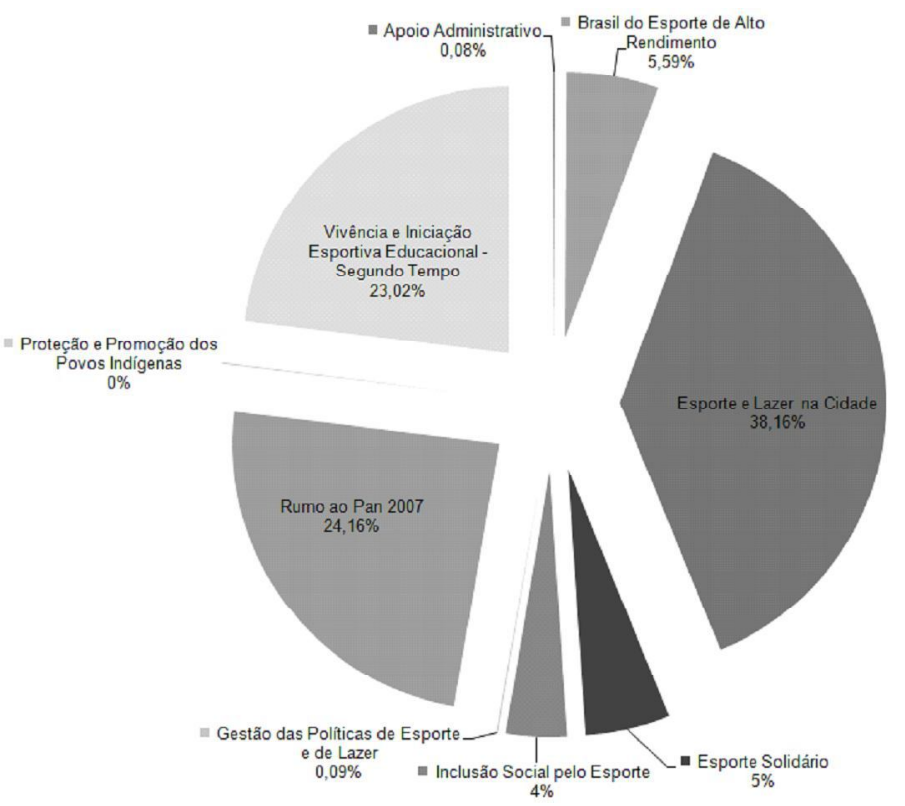

Figura 2: Gráfico percentual da finalidade dos recursos repassados aos Estados brasileiros por programa de esporte e lazer - 2004-2008

Fonte: A autora (2010) com base nos dados de Controladoria-Geral da União (2004b; 2005b; 2006b; 2007b; 2008b).

Movimento, Porto Alegre, v. 16, n. 04, p. 73-92, outubro/dezembro de 2010. 


\section{Artigos Originais Bárbara de Almeida e Wanderley M. Júnior}

Quando se trata de repasse aos estados e municípios, o investimento em esporte participação e esporte educacional totaliza $61 \%$ dos recursos. Os programas de alto rendimento somam $29 \%$.

Embora o investimento por essa via supere em mais de $\mathrm{R} \$ 1$ bilhão as verbas investidas pelos órgãos superiores e haja um relevante incremento para o esporte educacional e participação, o programa "Rumo ao Pan 2007" ainda teve a maior quantidade de recursos no período, como pode ser visto no gráfico a seguir.

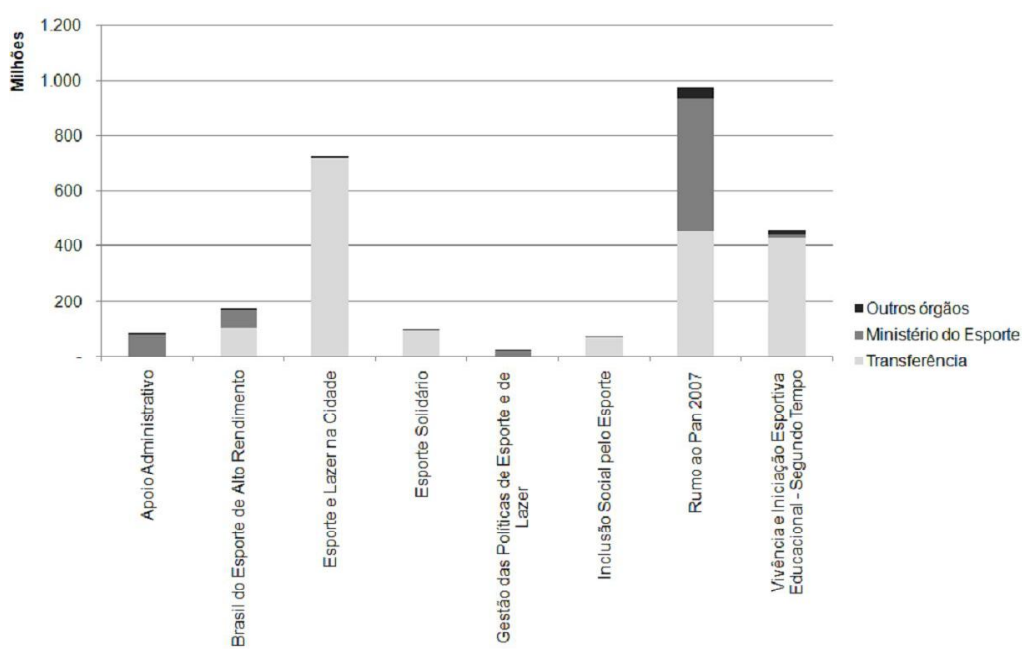

Figura 3: Gráfico de investimentos do Governo Federal em programas de esporte e lazer, considerando gastos ministeriais e repasses aos

Estados e Municipios - 2004-2008

Fonte: A autora (2010) com base nos dados de Controladoria-Geral da União (2004b; 2005b; 2006b; 2007b; 2008b).

O gráfico reforça a alta interferência dos repasses aos estados e municípios em várias ações. Por isso, podemos inferir que há uma relativa descentralização nos investimentos da área, o que nos provoca a levantar algumas hipóteses sobre aspectos positivos e negativos dessa situação que se apresentam como pontos passíveis de investigação pelos estudiosos de políticas públicas para o esporte e lazer.

Movimento, Porto Alegre, v. 16, n. 04, p. 73-92, outubro/dezembro de 2010. 
Como ponto positivo, vemos uma liberdade aos estados e municípios investirem conforme as especificidades da região, ainda que dentro das diretrizes dos programas federais. Mas, como ponto negativo, essa descentralização pode causar mudanças nos objetivos dos programas idealizados pelos técnicos do ME, já que a responsabilidade na administração dos recursos não é mais do gestor federal. Nesse sentido, vemos a possibilidade de investimentos para atender perspectivas de promoção e visibilidade político-partidárias em determinada região, por exemplo, com investimentos em infraestrutura e equipamentos esportivos.

Apresentados os dados sumários e o panorama de financiamento das ações federais de esporte e lazer de 2004 a 2008, além da exposição de conceitos chave do referencial teórico eleito, indicaremos algumas reflexões acerca deste quadro.

\section{DISCUSSÃo}

Pelo mapeamento dos caminhos dados aos recursos públicos em ações de esporte e lazer, foi possível perceber a tendência de manutenção de posições dominantes e dominadas no campo esportivo brasileiro. Mesmo com a realização do Rio 2007, esses cinco anos analisados foram o início de uma tendência de recursos investidos para a promoção dos chamados megaeventos esportivos (Copa do Mundo de futebol masculino em 2014 e os Jogos Olímpicos e Paraolímpicos de 2016 no Rio de Janeiro).

Abordamos duas vias para aplicação dos recursos públicos federais em esporte e lazer no país: pelos órgãos superiores (ME e outros órgãos superiores federais) e por transferências de recursos aos estados e municípios.

Observando especificamente as ações do ME, vimos que, no período de 2004 a 2008, 72\% dos recursos foram investidos no Rio 2007 e pouco menos de $7 \%$ da verba foi direcionada para ações relacionadas ao esporte participação e educacional. Já os outros ministérios aplicaram mais verbas em programas de esporte educacional e participação que o próprio ME.

Movimento, Porto Alegre, v. 16, n. 04, p. 73-92, outubro/dezembro de 2010. 


\section{Artigos Originais Bárbara de Almeida e Wanderley M. Júnior}

No somatório desses dados, os gastos do ME e dos outros ministérios em esporte de rendimento totalizaram $81 \%$ e menos de $8 \%$ para as manifestações de esporte educacional e participação.

Esse quadro se diferencia da transferência de recursos aos estados e municípios. Primeiro, porque, por essa via, os repasses chegam a $\mathrm{R} \$ 1,88$ bilhão, sendo a maior forma de investimento em esporte e lazer do governo federal. Segundo, porque $61 \%$ desses recursos foram investidos em programas das manifestações do esporte participação e educacional, enquanto $29 \%$ foram para ações de esporte de rendimento.

Apesar desta verba aplicada para fins educacionais e de participação, a realização do Rio 2007 se manteve como o maior investimento do governo federal no somatório do período, chegando ao valor de R \$ 975 milhões. Em seguida, está o programa "Esporte e Lazer na Cidade" com aproximadamente R \$ 730 milhões investidos e o programa "Vivência e Iniciação Esportiva Educacional - Segundo Tempo", com quase R \$ 460 milhões. Já o programa "Brasil no Esporte de Alto Rendimento" teve mais de R $\$ 175$ milhões em verbas.

Sob o olhar dessas vias de investimento, vemos que as prioridades do governo federal para o esporte e lazer foram para o esporte de alto rendimento, principalmente para a realização do Rio 2007. Esse quadro é adverso ao que estabelece a Constituição Federal de 1988, Artigo 217 e inciso II, quando coloca como prerrogativa a destinação prioritária de recursos públicos para o esporte educacional e, somente em casos específicos, para o esporte de alto rendimento.

Porém, a lei infraconstitucional $\mathrm{n}^{\circ} 9.615$ de 1998 (conhecida como Lei Pelé) em seu artigo $14^{\circ}$ estabelece:

\footnotetext{
Art. 14: O Comitê Olímpico Brasileiro-COB e o Comitê Paraolímpico Brasileiro, e as entidades nacionais de administração do desporto que lhes são filiadas ou vinculadas, constituem subsistema específico do Sistema Nacional do Desporto, ao qual se aplicará a prioridade prevista no inciso II do art. 217 da Constituição Federal, desde que seus estatutos obedeçam integralmente à Constituição $\mathrm{Fe}$ deral e às leis vigentes no País (BRASIL, 1998).
}

Movimento, Porto Alegre, v. 16, n. 04, p. 73-92, outubro/dezembro de 2010. 
Com isso, existe a lacuna jurídica para considerar investimentos em megaeventos, por exemplo, como os "casos específicos" para a exceção na destinação dos recursos. Pensando na realização do Rio 2007 e na série de grandes eventos esportivos que acontecerão até 2016, podemos inferir que presenciaremos mais de uma década de "casos específicos" para destinação de recursos prioritários para o esporte de alto rendimento. Mais do que isso, conforme a atual legislação, praticamente todas as manifestações de esporte de alto rendimento podem receber recursos prioritários, já que as entidades filiadas ou vinculadas (confederações de modalidades olímpicas e não olímpicas) também são consideradas no referido artigo 14.

Outro aspecto que dificulta a argumentação sobre tal situação é a ausência de uma política de estado para o esporte e lazer. Qual a prioridade do Estado brasileiro para as manifestações de esporte e lazer? A realização de um megaevento é uma política pública? Estas são algumas questões que se abrem para o debate quando tratamos os desafios impostos ao quadro atual e futuro para o financiamento público do esporte brasileiro.

Nesse ponto, é interessante notarmos a relação entre o $\mathrm{COB}$ e o governo federal. Esses agentes do campo esportivo não se relacionam somente pelo primeiro recebendo recursos financeiros do segundo, quando as ações ligadas ao COB, ou ao Comitê Organizador do Rio 2007 (ainda que as entidades tivessem praticamente os mesmos dirigentes), foram as principais fontes de investimento do governo federal.

Isso nos auxilia a pensar no COB como um dos dominantes do campo esportivo brasileiro. Entre as principais instituições que representam o esporte de rendimento no país, sua posição está sustentada pela importância do Movimento Olímpico na conjuntura internacional do esporte e também pelos interesses que o próprio governo tem com essa manifestação esportiva.

Nesse sentido, é válido pensar o esporte como um meio potencial de conquista simbólica dos jovens, com possibilidade de conversão em capital político (BOURDIEU, 1983). Aqui podemos questionar

Movimento, Porto Alegre, v. 16, n. 04, p. 73-92, outubro/dezembro de 2010. 
se são somente os jovens que são conquistados pelo esporte, senão todas as pessoas que o compreendem dentro de perspectivas exclusivamente benéficas da "mão esquerda" do Estado, como sua relação com promoção de saúde e/ou meio de resolver problemas como violência, uso de drogas e ociosidade.

Incrementamos ainda a possibilidade de pensar na estratégia de utilização do esporte como meio de promover um sistema político ou um país. O uso do esporte para fins políticos é um assunto constantemente estudado em se tratando de governos ditatoriais ou envolvidos em guerras. Entretanto, também se pode apropriar para $o$ atual contexto brasileiro.

O governo federal do período teve (e tem) uma estratégia de posicionamento mundial, possível de inferir através de seus discursos e ações, ainda que não existam pesquisas comprovando essa disposição. Nesse objetivo, o esporte pode ter um papel chave quando trata de disputas miméticas de poder entre diferentes países.

Vemos que, para que sua exibição seja mundial, não basta que o investimento tenha impacto somente no público interno, como seria para as manifestações de participação e educacional. Aí vemos uma possibilidade de interpretação sobre a iniciativa de sediar megaeventos esportivos, por onde se espera demonstrar poder para os demais países do mundo.

Somados esses fatores, os repasses do governo federal podem ser considerados pequenos, em comparação a outros tipos de gastos, pelo potencial retorno sob a forma simbólica que o esporte é capaz de promover.

No campo do esporte brasileiro, vimos que um importante objeto de disputas é o capital econômico. Mas também há uma busca de conquistas simbólicas através do esporte, variável para cada agente envolvido.

O ME atualmente pode ser considerado como duplamente dominado, tanto no campo político (onde o esporte está na mão esquerda), quanto no campo esportivo, onde as ações de esporte de rendimento, que são administradas também pelo $\mathrm{COB}$, ofuscam as

Movimento, Porto Alegre, v. 16, n. 04, p. 73-92, outubro/dezembro de 2010. 
demais ações. Ainda assim, podemos inferir que há resistência (ou uma tentativa de sobrevivência) a essa posição pela aproximação com outros ministérios para o desenvolvimento de projetos relacionados às outras manifestações esportivas.

$\mathrm{Na}$ investigação realizada, foi possível perceber que existem alguns pontos que carecem discussão, principalmente sobre as prioridades do Estado no desenvolvimento de determinadas manifestações do esporte.

Os dados aqui colocados demonstram que o esporte de rendimento é prioritário no recebimento de recursos pelo poder público federal brasileiro. Isto posto, corroborando as observações de Bourdieu quanto a relação do esporte com a política, observamos que, acima do bem comum e do interesse na população - aspectos que a política pública para o esporte deveria visar -, a conquista e a manutenção de poder político são os objetivos que vão além dos interesses do campo esportivo.

Movimento, Porto Alegre, v. 16, n. 04, p. 73-92, outubro/dezembro de 2010. 


\section{Artigos Originais Bárbara de Almeida e Wanderley M. Júnior}

Financing of the sport and leisure Federal Programs in Brazil (2004 to 2008)

Abstract: In this research, we propose to answer two questions: how much money sport and leisure programs received from federal government of Brazil through direct investments and transferences to states and cities between 2004 and 2008? Which facts can justify the priority investments of the federal government in these five years? Collecting data from the Union's General Controllership, we exposed that the investments had as priority high level sport. With Pierre Bourdieu reflexive sociology contribution, we outline some reasons related to the comprehension of politic field logics to understand this priority during these years.

Keywords: Politics. Sports. Financing, Government. Brazil.

\begin{tabular}{|l|}
\hline La financiación de los Programas Federales de \\
deporte y ócio en Brasil (2004 a 2008) \\
Resumen: Nos ponemos en esta investigación para \\
responder las siguientes preguntas: ¿cuánto los pro- \\
gramas de deporte y ocio han recibido en forma de \\
gastos directos del gobierno federal brasileño y por \\
transferencias a estados y municipios entre 2004 y \\
2008 ?Qué factores pueden justificar las priorida- \\
des de inversión durante eses años? A través de la \\
recopilación de datos de la Contraloría General de la \\
Unión, se muestra que la suma invertida ha dado \\
prioridad al deporte de elite. Con la colaboración de \\
Pierre Bourdieu, esbozamos algunas justificativas \\
para esa prioridad envolviendo la comprensión de las \\
lógicas del campo político. \\
Palabras-clave: Política. Deportes. Financiación \\
Gubernamental. Brasil.
\end{tabular}

\section{REFERÊNCIAS}

BOURDIEU, Pierre. Como se pode ser esportivo? In: QUESTÕES de Sociologia. Tradução Jeni Vaitsman. Rio de Janeiro: Marco Zero, 1983.

Contrafogos: táticas para enfrentar a invasão neoliberal. Tradução Lucy Magalhães. Rio de Janeiro: Jorge Zahar, 1998. Título original em francês:

BOURDIEU, Pierre. (Coord.). Miséria do mundo. Tradução Mateus S. Soares Azevedo. Rio de Janeiro: Vozes, 2003. Título original em francês:

Movimento, Porto Alegre, v. 16, n. 04, p. 73-92, outubro/dezembro de 2010. 
Da casa do rei à razão de Estado: um modelo da gênese do campo burocrático. In: WACQUANT, Loïc (Org.). O mistério do ministério: Pierre Bourdieu e a política democrática. Trad. Paulo Cezar Castanheira. Rio de Janeiro: Revan, 2005.

BOURDIEU, Pierre; WACQUANT, Loïc. Una invitación a la sociología reflexiva. Traducción Ariel Dilon. Buenos Aires: Siglo XXI Editores Argentina, 2005.

BRASIL. [Constituição, 1988]. Constituição da República Federativa do Brasil. Brasília, 2006. Disponível em: <http://www.senado.gov.br/sf/legislacao/const/ con1988/CON1988_05.10.1988/CON1988.pdf> Acesso em: 08 abr. 2008.

BRASIL. Casa Civil. Lei no 9.615 de 24 de março de 1998. Institui normas gerais sobre desporto e dá outras providências. Diário Oficial da República Federativa do Brasil. Brasília DF, 25 mar. 1998. Disponível em: <http://www.planalto.gov.br/CCIVIL/ Leis/L9615Compilada.htm>. Acesso em: 19 ago. 2009.

BRASIL. Ministério do Esporte. Institucional. histórico. Disponível em: <http:// portal.esporte.gov.br/institucional/historico.jsp>. Acesso em: 5 jan. 2009.

CARVALHO, José Carlos de Oliveira. Orçamento público: teoria e questões atuais comentadas. 2. ed. Rio de Janeiro: Elsevier, 2007.

CONTROLADORIA-GERAL DA UNIÃO. Portal da transparência: gastos diretos por ação governamental 2004a. Disponível em: $\leq$ http://arquivos.portalda transparencia.gov.br/PortalTransparenciaEscolheTipoDePlanilha. asp?origem $=$ PortalComprasDiretasPesquisa Acao\&Exercicio=2004>. Acesso em: 08 abr. 2010.

Portal da transparência: transferência de recursos por ação de governo 2004b. Disponível em: <http://arquivos.portaldatransparencia.gov.br/Portal TransparenciaEscolheTipoDePlanilha.asp?origem=Portal Transparencia Pesquisa Acao \& Exercicio=2004>. Acesso em: 08 abr. 2010.

Portal da transparência: gastos diretos por ação governamental 2005a. Disponível em:shttp://arquivos.portaldatransparencia.gov.br/Portal Transparencia EscolheTipoDePlanilha.asp?origem=PortalCompras Diretas Pesquisa Acao \&Exercicio=2005>. Acesso em: 08 abr. 2010.

. Portal da transparência: transferência de recursos por ação de governo 2005b. Disponível em:<http://arquivos.portaldatransparencia.gov.br/Portal TransparenciaEscolheTipoDePlanilha.asp?origem=PortalTransparencia PesquisaAcao\&Exercicio=2005>. Acesso em: 08 abr. 2010.

Portal da transparência: gastos diretos por ação governamental 2006a. Disponível em: <http://arquivos.portaldatransparencia.gov.br/PortalTransparencia EscolheTipoDePlanilha.asp?origem=PortalComprasDiretasPesquisa Acao\& Exercicio=2006 >. Acesso em: 08 abr. 2010.

. Portal da transparência: transferência de recursos por ação de governo 2006b. Disponível em: $\leq$ http://arquivos.portaldatransparencia.gov.br/Portal

Movimento, Porto Alegre, v. 16, n. 04, p. 73-92, outubro/dezembro de 2010. 


\section{Artigos Originais Bárbara de Almeida e Wanderley M. Júnior}

TransparenciaEscolheTipoDePlanilha. asp? origem=PortalTransparenciaPesquisa Acao\&Exercicio $=2006>$. Acesso em: 08 abr. 2010.

Portal da transparência: gastos diretos por ação governamental 2007a. Disponível em: <http://arquivos.portaldatransparencia.gov.br/PortalTransparencia EscolheTipoDePlanilha.asp?orige $=$ PortalComprasDiretas Pesquisa Acao\&Exercicio $=2007>$. Acesso em: 08 abr. 2010.

Portal da transparência: transferência de recursos por ação de governo 2007b. Disponível em:<http://arquivos.portaldatransparencia.gov.br/ PortalTransparenciaEscolheTipoDePlanilha.asp?origem=PortalTransparenciaPesquisa Acao\&Exercicio=2007>. Acesso em: 08 abr. 2010.

Portal da transparência: gastos diretos por ação governamental 2008a. Disponível em:<http://arquivos.portaldatransparencia.gov.br/PortalTransparencia EscolheTipoDePlanilha.asp?origem =PortalComprasDiretasPesquisaAcao \&Exercicio=2008>. Acesso em: 08 abr. 2010.

Portal da transparência: transferência de recursos por ação de governo 2008b. Disponível em: shttp://arquivos.portaldatransparencia.gov.br/ PortalTransparenciaEscolheTipoDe Planilha. asp?origem = PortalTransparencia PesquisaAcao \&Exercicio=2008>. Acesso em: 08 abr. 2010.

Portal da transparência: sobre o portal. Disponível em: $\leq$ http:// www.transparencia.gov.br/sobre/>. Acesso em: 08 abr. 2010.

SILVA, E. L. da; MENEZES, E. M. Metodologia da pesquisa e elaboração da dissertação. 3. ed. Florianópolis: Laboratório de Ensino a Distância da UFSC, 2001

WACQUANT, Loïc. (Org.). 0 mistério do ministério: Pierre Bourdieu e a política democrática. Tradução Paulo Cezar Castanheira. Rio de Janeiro: Revan, 2005.

Recebido em: 02.05.2010

Aprovado em: 12.07 .2010

Movimento, Porto Alegre, v. 16, n. 04, p. 73-92, outubro/dezembro de 2010 